\title{
Past Performance is Indicative of Future Beliefs
}

\section{Philip Z. Maymin and Gregg S. Fisher}

\section{Draft as of January 24, 2011}

\begin{abstract}
The performance of the average investor in an asset class lags the average performance of the asset class itself by an average of 1.95 percent per year over the past fifteen years, based on net investor cash flows of 25,000 mutual funds. We present a model in which a representative behavioral investor believes next year's returns will exactly match last year's returns and show that this leads to price adjustments on what would otherwise be random walk securities that effectively lower the future return of high performers and raise the future return of poor performers. The average predicted behavioral lag indeed matches the observed lag when asset returns are lognormally distributed with a mean and standard deviation equivalent to historical fifteen year averages of six percent and eighteen percent, respectively. In other words, investors chase returns and in doing so create the conditions of their own demise.
\end{abstract}

\section{Contact Information}

Philip Maymin (contact author)

Assistant Professor of Finance and Risk Engineering

NYU-Polytechnic Institute

Six MetroTech Center

Brooklyn, NY 11201

phil@maymin.com

(203)918-8047

Gregg S. Fisher

President and Chief Investment Officer

Gerstein Fisher

100 William Street

New York, NY 10038

gfisher@gersteinfisher.com

(212)968-0707 x111 


\section{Introduction}

The S\&P 500 earned a 6.75 percent annualized return over the past fifteen years but the average investor would not have received all of this performance. Figure 1 shows how this raw S\&P 500 return decomposes.

\section{Figure 1: Decomposition of $6.75 \%$ Annualized S\&P 500 Return for the fifteen years ending October 2010}

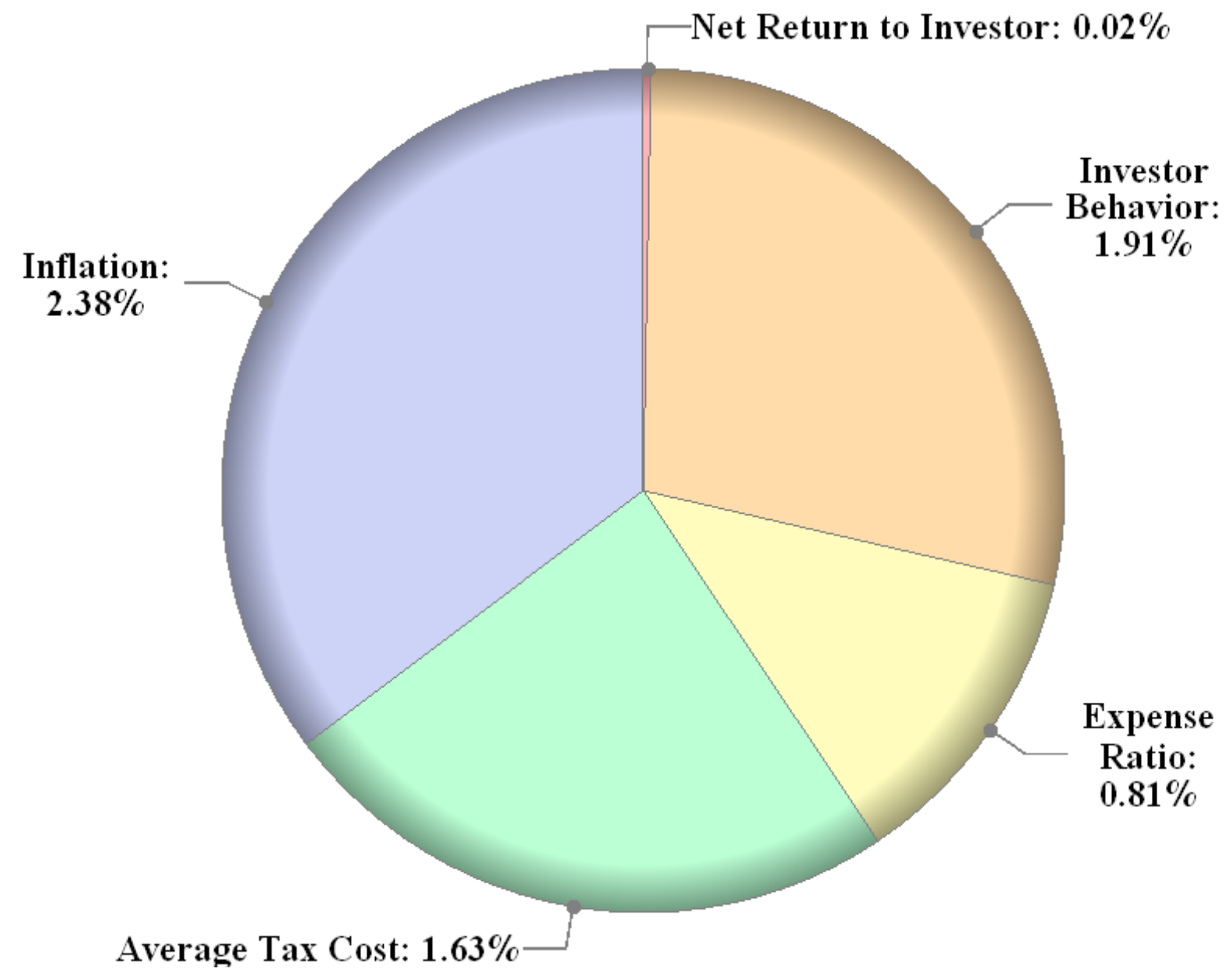

The largest chunk of the return is inflation's 2.38 percent, measured as the annualized Consumer Price Index over the time period. The average tax cost is calculated assuming a 35 
percent income tax and a 15 percent capital gains tax on annual profits. The expense ratio of all 25,046 mutual funds in the Morningstar database as of October 2010 averaged 0.81 percent.

This appears to leave a 1.93 percent real return net of taxes and fees to the investor. However, investors in funds tend to underperform the funds themselves because they tend to exit before gains and enter before losses. Investors who had simply remained invested in the S\&P 500 without any attempts to time the market would indeed have earned 1.93 percent net of inflation, taxes, and fees. But the average investor hurt himself by attempting to time entry and exit, losing on average 1.91 percent from such activity. Over the past fifteen years, such investors would have barely broken even, earning 0.02 percent per year. In other time periods, they can end up losing money in bull markets solely due to their trading tendencies.

Why is it that investors who attempt to time the market end up doing so poorly? In principle, investors who do the precise opposite of their natural inclinations could earn 1.91 percent on an annualized basis rather than losing it, thus ending with a net return of 3.84 percent. At the very least, investors who did no trading at all should have earned 1.93 percent.

We argue that the essence of the investor's trading strategy is to replace recent underperformers with recent outperformers. For example, figure 2 graphs the S\&P 500 and the excess of the net inflows to bond funds over the net inflows to equity funds across the past fifteen years. Peak inflows to bond funds occur after market corrections such as in 2002 and recently in 2008-2009. In other words, when one asset class underperforms another, individuals tend to switch from the former to the latter. 


\section{Figure 2: S\&P 500 (blue line) versus Excess Net Inflow to Bond Funds over Equity Funds (red area)}

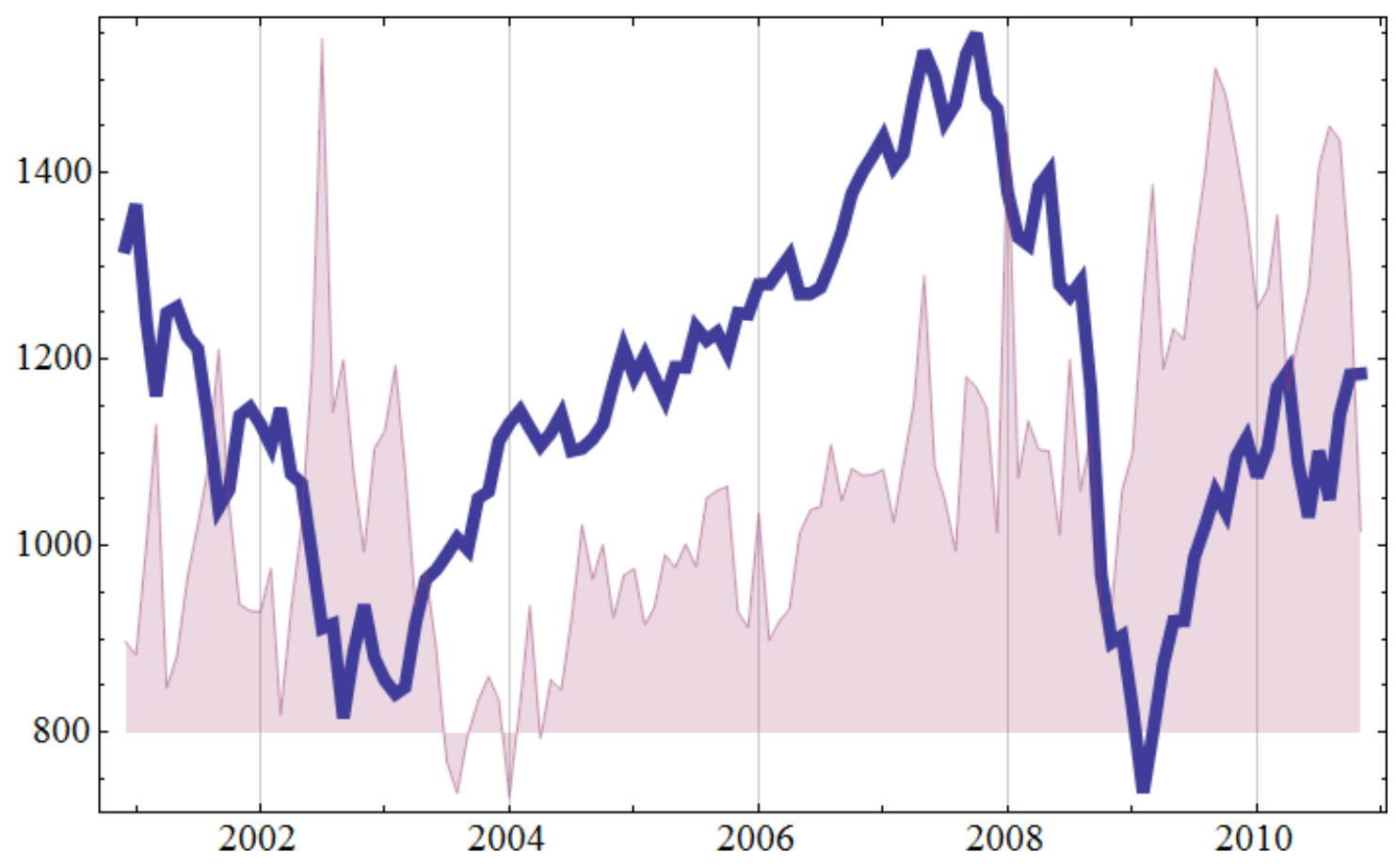

Ben-Rephael, Kandel, and Wohl (2011) document that shifts between bond and equity funds generate short-term price movements that are reversed within a few months. They interpret this as evidence of noise in aggregate market prices. We will instead interpret this in the context of our model of investors who hurt their own performance by shifting assets away from recent losers and into recent winners, specifically investors for whom past performance is indicative of their future beliefs.

Our paper contributes to the extant literature on this phenomenon by demonstrating how the investor reallocation activity may itself be generating the very underperformance that plagues the investors. 
Frazinni and Lamont (2008) examine the period of 1980-2003 and document that high individual investor sentiment predicts low future expected returns. They estimate that reallocations cost an average of 0.85 percent in using an average of 2,159 equity-only mutual funds per year. They argue that this evidence suggest simply that investors are dumb and making a mistake. In contrast, we use available mutual fund data rather than only equity funds, and focus on the most recent fifteen years. Further, we present a specific model of investor behavior that not only matches the empirical results, but shows that the investors are not simply routinely unlucky, but that their trading activity is the actual and proximate cause of their lowered earnings.

Friesen and Sapp (2007) examine 7,125 equity mutual funds in the period of 1991-2004 and find that reallocations cost an average of 1.56 percent annually. They find that poor investor behavior is significantly associated with risk-adjusted excess return but that the higher alpha is essentially erased by the behavioral trading decisions. Our universe is somewhat more recent and broader, including mutual funds from all asset classes, but note that Friesen and Sapp also report that they separately tested bond mutual funds and money market mutual funds and found a nearly zero performance gap. They conclude that their results are consistent with return-chasing behavior. However, they do not posit a specific model of investor behavior, as we do here, and they do not acknowledge the possibility that the trading activity of individual investors may itself be the cause of their underperformance.

Braverman, Kandel, and Wohl (2005) do present a model to explain this phenomenon. They propose an overlapping-generations model with two groups of investors, one of whom is 
always in the market and the other of whom may enter and exit the market for long periods, who differ in their demand. Here, however, we show that the results hold even if there is only one type of investor; indeed, even if there is only a single representative investor who chases returns, he will end up performing worse than he would have if he were a single representative buy-and-hold investor.

\section{Model}

Simulated securities are independently and identically distributed with lognormal returns having an annual mean return of $\mu$ and an annualized standard deviation of $\sigma$. Returns are drawn every monthly, so $d t=1 / 12$, over a period of $T$ years, and there are $N$ different securities.

However, a representative investor has a time horizon of one year and believes that last year's realized return is next year's expected return. The investor rebalances his position monthly and his rebalancing affects prices in such a way that their remaining expected returns, from his perspective, are $\mu$. For simplicity, and because estimates of volatility are more precise than estimates of drift (Merton, 1980), the investor always believes future volatility will be the true volatility $\sigma$.

For example, when the representative investor observes that a security has increased by ten percent last year, he believes the security has an expected return of ten percent in the subsequent year. If the required expected return is $\mu=0.06$, then he will increase the price by $1.10 / 1.06-1=0.0377$, or just under four percent. After doing so, the remaining return from 
the perspective of the representative investor is precisely $\mu$, so he will become indifferent to any further purchases or sales of the outperformer.

In other words, the post-rebalancing outperformance of a security comprises two portions: the first portion is the actual random performance that it experienced last year, and the second portion is the amount by which the representative investor bids up the security because of the erroneous expectation that past performance is indicative of future results. If the random performance were $r$, and the required expected return were $\mu$, this second portion of the observed return would be $(1+r) /(1+\mu)-1$. Averaged across time, this represents the amount the investor lost if positive (or gained if negative) by overpaying for a security that would by construction fail to repeat its prior performance. In other words, it is the behavioral trading costs of the representative investor, comparable to the 1.95 percentage point average observed loss described in the previous section.

Consider the results when there is only one security and the time horizon is $T=20$ years. Table 1 shows the average behavioral trading costs for 100,000 simulations for various values of $\mu$ and $\sigma$. The highlighted box represents $\mu=.06$ and $\sigma=.18$, matching the average past fifteen year results of a variety of assets to within one-half of a standard error. 


\section{Table 1: Simulated Behavioral Trading Costs}

All numbers below are in percentages. The first number is the average behavioral trading cost of chasing returns and the second number [in brackets] is the standard error.

\begin{tabular}{ccccccccccc}
\hline & $\boldsymbol{\sigma = 8}$ & $\boldsymbol{\sigma = 1 0}$ & $\boldsymbol{\sigma = 1 2}$ & $\boldsymbol{\sigma = 1 4}$ & $\boldsymbol{\sigma = 1 6}$ & $\boldsymbol{\sigma = 1 8}$ & $\boldsymbol{\sigma = 2 0}$ & $\boldsymbol{\sigma = 2 2}$ & $\boldsymbol{\sigma = 2 4}$ & $\boldsymbol{\sigma = 2 6}$ \\
\hline $\boldsymbol{\mu = 0}$ & 0.07 & -0.02 & 0.01 & 0.12 & 0.05 & -0.11 & 0.12 & 0.00 & 0.01 & -0.26 \\
& {$[0.09]$} & {$[0.11]$} & {$[0.13]$} & {$[0.15]$} & {$[0.18]$} & {$[0.20]$} & {$[0.22]$} & {$[0.24]$} & {$[0.27]$} & {$[0.29]$} \\
$\boldsymbol{\mu = 1}$ & 0.08 & -0.02 & 0.09 & 0.06 & 0.03 & 0.15 & 0.11 & -0.01 & 0.08 & 0.15 \\
& {$[0.09]$} & {$[0.11]$} & {$[0.13]$} & {$[0.15]$} & {$[0.18]$} & {$[0.20]$} & {$[0.22]$} & {$[0.24]$} & {$[0.27]$} & {$[0.29]$} \\
$\boldsymbol{\mu = \mathbf { 2 }}$ & 0.15 & 0.28 & 0.25 & 0.28 & 0.17 & 0.31 & 0.43 & 0.21 & 0.32 & 0.35 \\
& {$[0.09]$} & {$[0.11]$} & {$[0.13]$} & {$[0.15]$} & {$[0.18]$} & {$[0.20]$} & {$[0.22]$} & {$[0.24]$} & {$[0.27]$} & {$[0.29]$} \\
$\boldsymbol{\mu = 3}$ & 0.60 & 0.57 & 0.61 & 0.62 & 0.43 & 0.82 & 0.65 & 0.48 & 0.50 & 0.36 \\
& {$[0.09]$} & {$[0.11]$} & {$[0.13]$} & {$[0.15]$} & {$[0.18]$} & {$[0.20]$} & {$[0.22]$} & {$[0.24]$} & {$[0.27]$} & {$[0.29]$} \\
$\boldsymbol{\mu}=\mathbf{4}$ & 0.92 & 0.82 & 0.98 & 0.95 & 0.95 & 0.83 & 0.78 & 1.06 & 0.75 & 1.11 \\
& {$[0.09]$} & {$[0.11]$} & {$[0.13]$} & {$[0.15]$} & {$[0.18]$} & {$[0.20]$} & {$[0.22]$} & {$[0.24]$} & {$[0.27]$} & {$[0.29]$} \\
$\boldsymbol{\mu}=\mathbf{5}$ & 1.36 & 1.53 & 1.52 & 1.47 & 1.29 & 1.26 & 1.57 & 1.10 & 0.95 & 1.61 \\
& {$[0.09]$} & {$[0.11]$} & {$[0.13]$} & {$[0.15]$} & {$[0.18]$} & {$[0.20]$} & {$[0.22]$} & {$[0.24]$} & {$[0.27]$} & {$[0.29]$} \\
$\boldsymbol{\mu}=\mathbf{6}$ & 2.13 & 2.09 & 2.13 & 1.82 & 1.96 & 2.03 & 2.34 & 2.12 & 2.16 & 2.05 \\
& {$[0.09]$} & {$[0.11]$} & {$[0.13]$} & {$[0.15]$} & {$[0.18]$} & {$[0.20]$} & {$[0.22]$} & {$[0.24]$} & {$[0.27]$} & {$[0.29]$} \\
$\boldsymbol{\mu}=\mathbf{7}$ & 2.78 & 2.86 & 2.84 & 2.83 & 2.93 & 2.72 & 2.82 & 2.82 & 2.77 & 2.96 \\
& {$[0.09]$} & {$[0.11]$} & {$[0.13]$} & {$[0.15]$} & {$[0.18]$} & {$[0.20]$} & {$[0.22]$} & {$[0.24]$} & {$[0.27]$} & {$[0.29]$} \\
$\boldsymbol{\mu}=\mathbf{8}$ & 3.62 & 3.74 & 3.63 & 3.69 & 3.81 & 3.71 & 3.53 & 3.32 & 3.78 & 3.62 \\
& {$[0.09]$} & {$[0.11]$} & {$[0.13]$} & {$[0.15]$} & {$[0.18]$} & {$[0.20]$} & {$[0.22]$} & {$[0.24]$} & {$[0.27]$} & {$[0.29]$} \\
$\boldsymbol{\mu}=\mathbf{9}$ & 4.60 & 4.55 & 4.52 & 4.65 & 4.46 & 4.40 & 4.58 & 4.60 & 4.75 & 4.40 \\
& {$[0.09]$} & {$[0.11]$} & {$[0.13]$} & {$[0.15]$} & {$[0.18]$} & {$[0.20]$} & {$[0.22]$} & {$[0.24]$} & {$[0.27]$} & {$[0.29]$} \\
$\boldsymbol{\mu = 1 0}$ & 5.75 & 5.58 & 5.65 & 5.67 & 5.57 & 5.85 & 5.87 & 5.45 & 5.78 & 5.53 \\
& {$[0.09]$} & {$[0.11]$} & {$[0.13]$} & {$[0.15]$} & {$[0.18]$} & {$[0.20]$} & {$[0.22]$} & {$[0.24]$} & {$[0.27]$} & {$[0.29]$} \\
\hline
\end{tabular}

\section{Data}

Taking the 24,719 mutual funds from Morningstar data that had at least some assets data and some returns data during the past fifteen years, we calculate the rolling annual fund returns and average investor returns using the calculations described in Appendix A. For each rolling window of 13 months (the first month is required to know the initial asset size), we require complete data on assets and on returns. However, to minimize possible survivorship bias, we only require this complete data on each 13-month rolling window; we do not require funds to have all data for every month for the past fifteen years. 
Figure 3 plots the equally weighted average trailing annual behavioral cost across all mutual funds for each month. It is virtually always a net cost, with occasional very high peaks.

Figure 3: Equally Weighted Average Behavioral Trading Costs

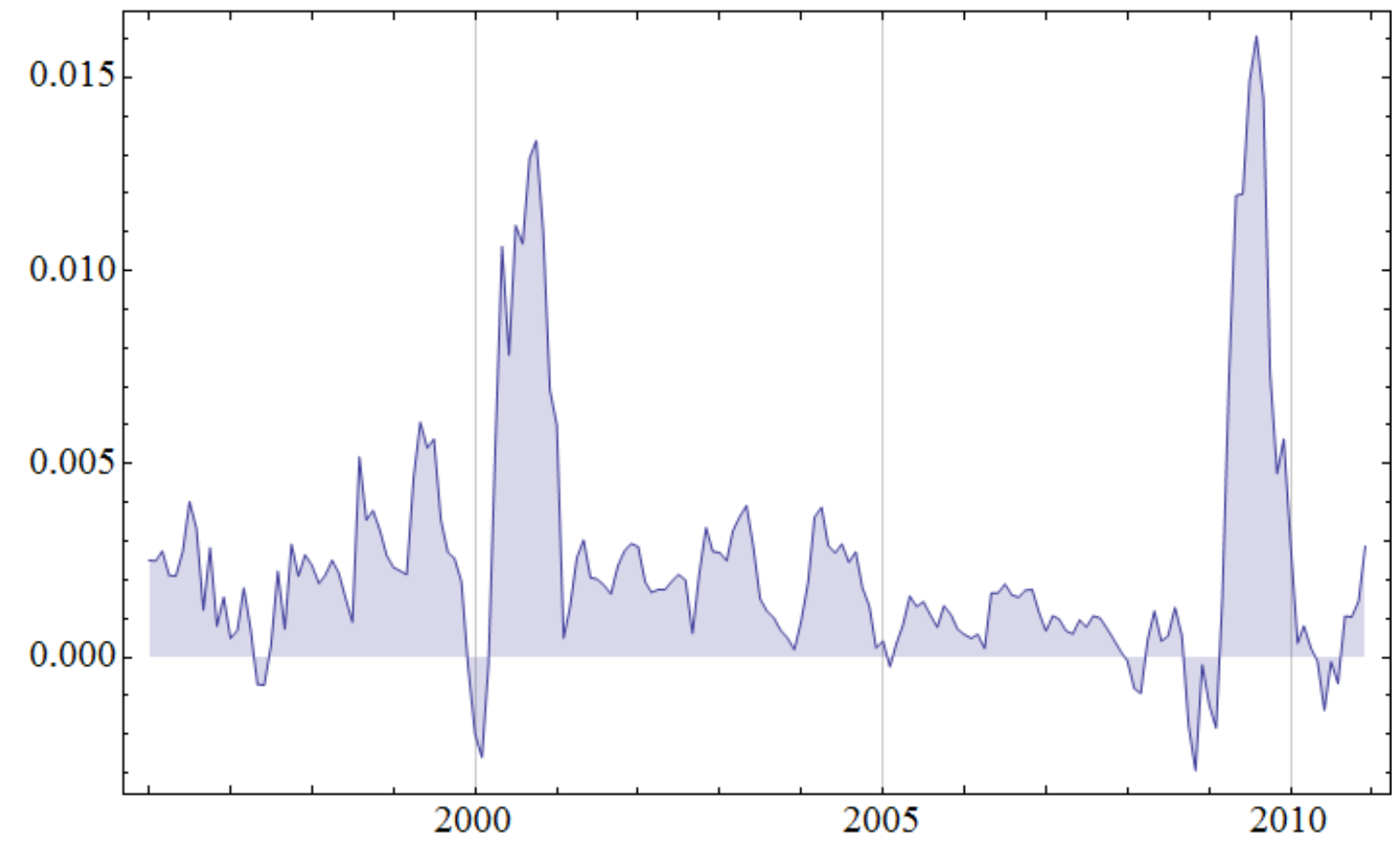

\section{Conclusion}

Future research could include a positive required expected return for all securities, or a required Sharpe ratio for each security to adjust the expected return for the security's volatility. Furthermore, following the empirical and theoretical results of Maymin and Maymin (2010), the representative investor could be mistaken not only about estimates of expected return but also about estimates of volatility. These errors could lead to more complex interactions between past performance and present price adjustments on the basis of erroneous future 
forecasts. Finally, multiple investors or investor types could be introduced to make more specific predictions about trading volume and price impact.

\section{References}

Ben-Rephael, Azi and Shmuel Kandel and Avi Wohl (2011). "Measuring Investor Sentiment with Mutual Fund Flows." Journal of Financial Economics, forthcoming.

Braverman, Oded and Shmuel Kandel and Avi Wohl (2005). "The (Bad?) Timing of Mutual Fund Investors." Unpublished working paper, retrieved from http://www.econpol.unisi.it/labsi/papers2006/Kandel.pdf.

Frazzini, Andrea and Owen Lamont (2008). "Dumb money: Mutual fund flows and the crosssection of stock returns." Journal of Financial Economics 88, 299-322.

Friesen, Geoffrey C. and Travis R.A. Sapp (2007). "Mutual fund flows and investor returns: An empirical examination of fund investor timing ability." Journal of Banking and Finance 31, 2796-2816.

Merton, Robert C. (1980). "On Estimating the Expected Return on the Market: An Exploratory Investigation." Journal of Financial Economics 8:4, 323-361.

Maymin, Philip Z. and Zakhar G. Maymin (2010). "Any Regulation of Risk Increases Risk." Working Paper available on http://ssrn.com/abstract $=1587043$.

\section{A. Calculation of Fund Returns and Investor Returns}

Given a list of 13 consecutive monthly assets $a_{0} . a_{12}$ and corresponding monthly returns $r_{0} . . r_{12}$ for a particular fund, the total yearly fund return $R_{\text {Fund }}$ is computed as:

$$
R_{\text {Fund }}=\prod_{i=1}^{12}\left(1+r_{i}\right)-1
$$

The average investor return is solved numerically as the internal rate of return required such that the investor who started with assets $a_{0}$ would have ended with the final assets $a_{12}$ 
after adjusting for all of the intermediate cashflows $a_{i}-a_{i-1}\left(1+r_{i}\right)$ for $i=1 . .12$. Specifically, if $r_{I R R}$ is the numerical solution satisfying the following:

$$
a_{0}+\sum_{i=1}^{12} \frac{a_{i}-a_{i-1}\left(1+r_{i}\right)}{\left(1+r_{I R R}\right)^{i}}-\frac{a_{12}}{\left(1+r_{I R R}\right)^{12}}=0
$$

then the yearly investor return $R_{\text {Investor }}$ is:

$$
R_{\text {Investor }}=\left(1+r_{I R R}\right)^{12}-1
$$

and the behavioral trading costs $C$ for that particular fund, for that particular time period, are:

$$
C=R_{\text {Fund }}-R_{\text {Investor }}
$$

